Boise State University

ScholarWorks

$1-1-2018$

Feeling Like a Fraud: Helping Students Renegotiate Their Academic Identities

Elizabeth Ramsey

Boise State University

Deana Brown

Boise State University 


\title{
Feeling Like a Fraud: Helping Students Renegotiate Their Academic Identities
}

\author{
Elizabeth Ramsey, MLS \\ Assistant Professor/Librarian \\ Albertsons Library at Boise State University \\ Boise, ID \\ elizabethramsey@boisestate.edu
}

\author{
Deana Brown, MLS \\ Assistant Professor/Librarian \\ Albertsons Library at Boise State University \\ Boise, ID \\ deanabrown@boisestate.edu
}

\begin{abstract}
A sense of belonging is an integral aspect of success in a long-term, group-oriented endeavor such as the pursuit of a college education. When students feel their presence at college is fraudulent, their achievements unfounded, or that they will be further disenfranchised if their true self is discovered, it is less likely that they will connect to the people and services who can help them achieve their educational goals. This "imposter syndrome" or "imposter phenomenon" can be addressed and turned around through a concerted effort. While that effort involves a personal journey, like any journey it is often aided and accompanied by others. Through strategic outreach efforts, academic libraries are positioned to be important players in that journey, helping these "imposters" renegotiate their self images to include a sense of their essential place in academia and belief in their ability to successfully complete their academic goals.
\end{abstract}

Keywords: academic libraries, outreach, retention, academic identity, imposter syndrome, imposter phenomenon

\section{Imposter Syndrome}

Imposter syndrome was first identified in high achieving women by Pauline Rose Clance and Suzanne Imes in 1978 when they found that women who experienced the syndrome "maintain a strong belief that they are not intelligent; in fact they are convinced that they have fooled anyone who thinks otherwise" (241) even in the face of contrary evidence such as degrees, awards, promotion, and tenure. Chance and Imes' research sample group included high achieving women in academia from undergraduates to faculty members. Other research since then has identified this inability to internalize accomplishments and its adverse effect on academic performance in a variety of student groups including: mature students (Chapman, 2015), ethnic minority students (Peteet, Montgomery and Weekes, 2015), and first generation students (Gardner and Holley, 2011), among others.

The common thread among the demographics represented in this research are aspects of identity from underrepresented groups at the average American university. Another commonality is the relatively lower rate of retention and graduation for many members of these groups. Research has shown that ethnic minorities (Murphy, et.al., 2010), the economically disadvantaged (Alon, 2007), first generation students (Pascarella, et.al., 2004), and women in certain academic programs (Cech, et.al., 2011) all have lower rates of academic persistence needed for graduation. While this research indicates myriad factors influencing the lower overall retention rates for these groups, imposter syndrome may certainly be counted among them.

The negative effects of imposter syndrome are many and varied. Brown and Ramsey noted that imposter syndrome stymies momentum out of a fear of failure (2015). Out of this fear "imposters" tend to either overwork, spending more time than necessary on assignments or underperform out of a sense of the inevitability of failure. Students with imposter syndrome also suffer from a fear of being discovered, identified as fraudulently admitted to university, and/or unable to fulfill classroom expectations. 
This is an author-produced, peer-reviewed version of this article. The final, definitive version of this document can be found online at College \& Undergraduate Libraries, published by Routledge. Copyright restrictions may apply. doi: 10.1080/10691316.2017.1364080

Cozzarelli and Major found that after failing, students suffering from imposter syndrome were less satisfied, felt worse, and were lower in measures of self-esteem than the "non-imposters" $(1990,413)$. In a sort of one-two punch, low selfesteem also has been proven to adversely affect the likelihood of college success generally (Grant-Vallone, et.al., 2007). In evidence more specific to women in engineering programs, Cech, et.al. also found a lack of confidence in expertise adversely affected female students’ persistence (2010).

Positive aspects of self-identity such as "optimism, perceptions of authenticity, self-acceptance and regard, and acceptance and regard of others" are strongly correlated to academic motivation and achievement according to Pajares (2001, 33). Holmegaard, et. al. also found that students who persisted with their university education had successfully negotiated not only who they were, but also their place within academia (2014). Other evidence also points to the development of a sense of belonging as essential to college success (Chapman, 2013). Imposter syndrome undermines the ability to negotiate a resilient academic identity and also impedes the growth of a sense of belonging. However, with determination and support, the "imposter" can overcome these barriers to their academic well-being and ultimate success.

\section{How to Resolve Imposter Syndrome}

College students suffering from imposter syndrome can take a number of steps to better integrate themselves into the social and academic fabric of college life. By doing so they may bolster their "fragile academic selves" (Knights and Clark, 2013) sufficiently to live up to their true potential and accomplish their academic goals.

Werner-Washburn and Gonzalez suggest that students should seek out mentors and other positive influences to help overcome imposter syndrome (2011). Richards, too, notes that "imposters" need reminders that they are not alone in fighting their feelings of inadequacy and not belonging (2015). Gill found that acting as a mentor herself was essential in the resolution of her imposter syndrome (2013). Martins and Anthony recommend that students give themselves a "reality check" (63) to identify evidence for the way they are thinking and what steps they might take to counter their sense of fraudulence. Martins and Anthony further suggest students find assistance from campus entities for stress and time management (2007).

\section{How Academic Libraries Can Help}

Libraries can help students renegotiate their academic identities and overcome imposter syndrome by: fostering mentors and other partnerships, connecting students to support services, modeling the resilience necessary for academic success, and making students feel welcome in library spaces.

Academic libraries can help foster the relationships shown to counter imposter syndrome by hosting meetings of inclusive clubs and social groups to help students find mentors and like- minded allies. Academic libraries may partner with academic support services to assist students in taking stock of their successes and looking at others objectively, tools in fighting feelings of inadequacy or not belonging. Another workshop idea might be to partner with campus support services to host or develop workshops devoted to connecting students to support for their physical and mental well-being. In many cases campus and academic support services are already undertaking these types of workshops. Academic libraries can still function as partners in these efforts by providing essential referral services and promotions for the workshops.

Interactions at the reference desk and during library instruction provide additional opportunities to support students suffering from imposter syndrome. Making mistakes during reference interviews and classroom presentations can be key moments in which academic librarians can model recovering from failure gracefully while maintaining momentum. Working through failure is an important skill for students even when they don't suffer from imposter syndrome. It's not uncommon during a reference consultation or classroom session to encounter frustration from students expecting to quickly find the "right" article when researching. Technology errors and research dead ends offer excellent opportunities to demonstrate the iterative nature of research, the fallibility of technology, and, perhaps most importantly, the fact that everyone eventually encounters "failure" when conducting research. Librarians who carefully script their search demonstrations for optimal outcomes are depriving students of essential learning moments that could increase self-confidence. Kwon noted the importance of these authentic moments by stating "In the 
This is an author-produced, peer-reviewed version of this article. The final, definitive version of this document can be found online at College \& Undergraduate Libraries, published by Routledge. Copyright restrictions may apply. doi: 10.1080/10691316.2017.1364080

beginning, students generally expressed weak critical thinking self-confidence and library anxiety. However, after experiencing the library and the research process, students seemed to gain confidence in both library use and their thinking abilities” (126).

Academic libraries that create inclusive atmospheres help enhance a sense of belonging in their students which can counter the "outsider" feelings inherent in imposter syndrome. Promotional materials should include images of mature students, ethnic minority students, and first generation students to counter their susceptibility to imposter syndrome. Spotlighting diverse students in leadership positions on social media posts can also help give "imposters" a sense of their place at university. Additionally, hiring a diverse cadre of student workers can create a welcoming environment in that students can see themselves reflected in those present in the library.

\section{Conclusion}

On the positive side, Knights and Clarke found the insecurities inherent in imposter syndrome "a mixed blessing because while they can be debilitating, they are also a driving force of our productive power that help generate high standards and pride in our work" (349). However, imposter syndrome largely works against the successful completion of academic goals. Academic libraries can contribute to the effort necessary to counter imposter syndrome through a variety of initiatives that support students as they find their place on campus, gain confidence in their abilities, and deepen their understanding of their evolving academic identity.

\section{References}

Alon, S. (2007). The Influence of Financial Aid in Leveling Group Differences in Graduating from Elite Institutions. Economics of Education Review, 26(3): 296-311.

Brown, Deana, and Elizabeth Ramsey. 2015. "Translating Failure into Success". PNLA Quarterly, 80(1): 16-19

Chapman, Amanda. 2013. "A (re) Negotiation of Identity: From 'Mature Student' to 'Novice Academic'." Widening Participation and Lifelong Learning 14(3): 44-61.

Chapman, Amanda. 2015. "Using the Assessment Process to Overcome Imposter Syndrome in Mature Students." Journal of Further and Higher Education 41(2): 112-119.

Clance, Pauline Rose, and Suzanne A. Imes. 1978. "The Imposter Phenomenon in High Achieving Women: Dynamics and Therapeutic Intervention." Psychotherapy: Theory, Research and Practice 1(3): 241-247.

Cozzarelli, Catherine and Brenda Major. 1990. "Exploring the Validity of the Impostor Phenomenon." Journal of Social and Clinical Psychology 9(4): 401-417.

Gardner, Susan K., and Karri A. Holley. 2011. "“Those Invisible Barriers Are Real”: The Progression of FirstGeneration Students through Doctoral Education." Equity \& Excellence in Education 4(1): 77-92.

Gill, Jacquelyn. 2013. "How I Cured My Imposter Syndrome.” Inside Higher Ed. June 16, 2013. Accessed February 28, 2017. https://www.insidehighered.com/blogs/university-venus/how-i-cured-my-imposter-syndrome.

Grant-Vallone, E., Reid, K., Umali, C., \& Pohlert, E. 2003. "An Analysis of the Effects of Self-Esteem, Social Support, and Participation in Student Support Services on Students' Adjustment and Commitment to College.” Journal of College Student Retention: Research, Theory \& Practice, 5(3): 255-274.

Holmegaard, Henriette Tolstrup, Lene Møller Madsen, and Lars Ulriksen. 2014. "A Journey of Negotiation and Belonging: Understanding Students’ Transitions to Science and Engineering in Higher Education." Cultural Studies of Science Education 9(3): 755-786.

Knights, David, and Caroline A. Clarke. 2013. "It’s a Bittersweet Symphony, This Life: Fragile Academic Selves and Insecure Identities at Work." Organization Studies. 35(3): 335-357.

Kwon, Nahyun. 2008. "A Mixed-Methods Investigation of the Relationship between Critical Thinking and Library Anxiety among Undergraduate Students in Their Information Search Process.” College \& Research Libraries. 69(2): 117-131.

Martins, Ros and Anthony. Lin. 2007. "Stepping Stones: A Guide for Mature Aged Students at University." Scevak, Jill, and Robert Cantwell, eds. 57-64. Camberwell, Vic.: ACER Press.

Murphy, T. E., Monica Gaughan, Robert Hume, R., \& S. Gordon Moore. 2010. College Graduation Rates for Minority Students in a Selective Technical University: Will Participation in a Summer Bridge Program Contribute to Success? Educational Evaluation and Policy Analysis, 32(1): 70-83.

Pajares, Frank. 2001. "Toward a Positive Psychology of Academic Motivation." The Journal of Educational Research 95(1): 27-35. 
This is an author-produced, peer-reviewed version of this article. The final, definitive version of this document can be found online at College

\& Undergraduate Libraries, published by Routledge. Copyright restrictions may apply. doi: 10.1080/10691316.2017.1364080

Pascarella, Ernest T., Christopher T. Pierson, Gregory C. Wolniak, and Patrick T. Terenzini. 2004. "First-Generation College Students: Additional Evidence on College Experiences and Outcomes." The Journal of Higher Education 75(3): 249-284.

Peteet, Bridgette J., LaTrice Montgomery, and Jerren C. Weekes. 2015. "Predictors of Imposter Phenomenon among Talented Ethnic Minority Undergraduate Students." The Journal of Negro Education 84(2): 175-186.

Richards, Carl. 2015. "Learning to Deal With the Impostor Syndrome." The New York Times. October 26, 2015. Accessed February 28, 2017. https://www.nytimes.com/2015/10/26/your-money/learning-to-deal-with-theimpostor-syndrome.html?_r=0. 